\title{
Precisione Treatment for Parvovirus B19 Infection After Hematopoietic Stem Cell Transplantation: a Case Report and Review of the Literature
}

\section{Xiaohui Zhou}

Shenzhen Children's Hospital https://orcid.org/0000-0002-0427-2164

\section{Wang Xiaodong}

Shenzhen Children's Hospital

Yu Uet

Shenzhen Children's Hospital

\section{Zhang Xiaoling}

Shenzhen Children's Hospital

Wang Chunjing

Shenzhen Children's Hospital

\section{Zhang Yu}

Shenzhen Children's Hospital

\section{Yang Chunlan}

Shenzhen Children's Hospital

\section{Luo Mingjing}

Shenzhen Children's Hospital

\section{Li Yue}

Shenzhen Children's Hospital

\section{Zhang Qian}

Shenzhen Children's Hospital

\section{Lin Zhenhu}

Shenzhen Children's Hospital

Jiang Xianping

Shenzhen Children's Hospital

Liu Sixi ( $\square$ tiger647@126.com )

Shenzhen Children's Hospital

\section{Case report}

Keywords: parvovirus B19, intravenous immunoglobulin, hematopoietic stem cell transplantation, case report 
Posted Date: May 4th, 2021

DOl: https://doi.org/10.21203/rs.3.rs-428338/v1

License: (c) (i) This work is licensed under a Creative Commons Attribution 4.0 International License. Read Full License 
1 Precisione treatment for parvovirus B19 infection after hematopoietic stem cell

2 transplantation : a case report and review of the literature

3 Xiaohui Zhou ${ }^{1 *}$, Xiaodong Wang ${ }^{1 *}$, Uet Yu$^{1}$, Xiaoling Zhang ${ }^{1}$, Chunjing Wang ${ }^{1}$, Yu

4 Zhang $^{1}$, Chunlan Yang ${ }^{1}$, Mingjing Luo $^{1}$, Yue $\mathrm{Li}^{1}$, Qian Zhang ${ }^{1}$, Zhenhu Lin ${ }^{2}$,

$5 \quad$ Xianping Jiang ${ }^{3}$, Sixi Liu ${ }^{1}$

6 1.Department of Hematology and Oncology, Shenzhen Children's Hospital, 7019

$7 \quad$ Yitian Road, Futian, Shenzhen, China, 518038

8 2. Institute for Medical Research, Shenzhen Children's Hospital, Shenzhen, China

9 3. Department of Pathology, Shenzhen Children's Hospital, Shenzhen, China

$10 *$ Shared first authors

\section{Corresponding author: Sixi Liu}

12 Email: tiger647@126.com

Tel: +86 189-3869-0206

Key words: parvovirus B19; intravenous immunoglobulin; hematopoietic stem cell 


\section{Abstract}

Background: Cytopenia due to parvovirus B19 (PVB19) infection has rarely been reported in recipients of thalassemia major after hematopoietic stem cell transplantation (HSCT). Most of the reported cases were patients undergone solid organ transplantation, especially renal transplant. However, cases of pediatric patients in thalassemia major have rarely been reported.

Case presentation: Here we report a girl that had PVB19-induced anemia while undergoing immunosuppressive therapy after transplant. The patient presented with progressive anemia and had a lowest hemoglobin level of $58 \mathrm{~g} / \mathrm{L}$. Bone marrow biopsy showed suppress inhibited erythropoiesis with giant pronormoblasts. Next-generation sequencing of peripheral blood suggested the infection of PVB19.The detection of serum PVB19-DNA using quantitative polymerase chain reaction revealed a viral load of over $1 \times 10^{8}$ copies $/ \mathrm{ml}$. The hemoglobin level increased to $113 \mathrm{~g} / \mathrm{L}$ after six courses of intravenous immunoglobulin (IVIG) therapy. Monitoring of viral load showed PVB19-DNA level remained at a low level for six months before clearance. Pure red cell aplasia was not observed during the treatment period.

Conclusions: Our case suggests that timely and adequately diagnosis and treatment against PVB19 with IVIG is effective and may prevent sequential complications in pediatric HSCT recipients.

Key words: parvovirus B19; intravenous immunoglobulin; hematopoietic stem cell transplantation; case report 


\section{Background}

Cytopenia is common complication but can cause severe outcomes in patients undergone hematopoietic stem cell transplantation (HSCT). Risk factors associated with the development of post-transplant cytopenia include the use of myelotoxic agents, viral infections, age of donors, human lymphocyte antigen compatibilities, CMV serostatuses of donor and recipient, and stem cell source[1-5]. Pure red cell aplasia (PRCA) caused by PVB19 infection has been sporadically reported in HSCT recipients[6]. However, cases of pediatric patients in thalassemia major have rarely been reported. In this study, we describe a case of girl that developed cytopenia due to PVB19 infection after HSCT.

\section{Case presentation}

This is a seven-year-old girl $\beta$-thalassemia major that received haploidentical HSCT at Shenzhen Children's Hospital in February 2019. The conditioning regimens consisted of cyclophosphamide (Cy), busulfan $(\mathrm{Bu})$, fludarabine (Flu), thiotepa(TT),rabbit anti-human thymocyte immunoglobulin (ATG). GVHD prophylaxis consisted of post-transplant cyclophosphamide (PTCY), tacrolimus (FK506), and mycophenolate mofetil (MMF), and short-term methotrexate (MTX)[7]. The patient presented with a progressive decrease of hemoglobin level from $110 \mathrm{~g} / \mathrm{L}$ to $58 \mathrm{~g} / \mathrm{L}$ within a two-month period starting from 15 weeks after transplantation. Fever was presented intermittent fever for three days, the highest body temperature is 38.8 degrees. The patient did not have graft versus host diseases (GVHDs). Physical examination showed signs of anemia and fatigue, and no other obvious positive signs. 
The immunosuppressive reagents are tacrolimus and methylprednisolone, the doses are $1 \mathrm{mg} \mathrm{q} 12 \mathrm{~h}$ and $6 \mathrm{mg}$ qd respectively. There was a reduction of reticulocyte count $\left(3.1 \times 10^{9} / \mathrm{L}, 0.1 \%\right.$ of total red blood cells) and elevated erythropoietin (EPO) level (312.04 $\mathrm{mIU} / \mathrm{mL}$, range 1.48 to $31.88 \mathrm{mIU} / \mathrm{mL}$ ). Quantitative polymerase chain reaction (Q-PCR) examination of CMV, Epstein-Barr virus (EBV)-DNA and hepatitis B virus were under the limit of detection. Autoimmune markers including CD71-positive nucleated red blood cells, CD15-positive granulocyte and CD34-positive primordial cell were not detected. There was a slight decrease of serum folic acid level (5.2ng/ml, rang more than 10.6ng/ml). Serum vitamin B12 and iron levels were within the normal range. Bone marrow examination was performed 7 days after the onset of symptoms.

The bone marrow aspiration shows that the number of erythroid cells is low; some of immature red blood cells are present with megablastic changes; gaint proerythroblasts appear in the aspirate; megakaryocytes and myeloid cells are normal (Figure 1).

The bone marrow biopsy showed mild hypoplasia of hematopoietic tissue, with a hematopoietic area of sixty percent (Figure 2). Immunohistochemistry examination of the cells revealed positive staining for CD235a(+), CD61(+), Lysozyme(+), MPO(+),PAS(+), EBERs(-). The patient was given folic acid supplementations and reduced the dose of immunesuppressants. However, anemia persisted and the patient developed pancytopenia, with reductions of platelet and leukocyte counts dropping from $188 \times 10^{9} / \mathrm{L}$ to $42 \times 10^{9} / \mathrm{L}$ and $5.25 \times 10^{9} / \mathrm{L}$ to $2.2 \times 10^{9} / \mathrm{L}$, respectively, a month after the presentation of anemia(Figure 3). However, short-tandem-repeat PCR 
examinations showed the patient remained full chimerism of donor graft during the disease course hence did not suggest the development of graft failure. Next generation sequencing of peripheral blood was then applied to find unconventional infections that could affect the process of erythropoiesis. An increased copy number of PVB19 was observed. Q-PCR examination of PVB19-DNA in the blood further indicated a high viral load of over $1 \times 10^{8}$ copies/mL. However, serological examination against PVB19 remained negative.

The patient was given intravenous immunoglobulin (IVIG) treatment for three consecutive days four days after the onset of symptoms. There was an increase of reticulocyte count $\left(97.6 \times 10^{9} / \mathrm{L}\right)$ and hemoglobin level $(91 \mathrm{~g} / \mathrm{L})$ a month after the IVIG treatment, accompanied by a significant reduction of blood PVB19-DNA copy numbers $\left(9.6 \times 10^{2}\right.$ copies $\left./ \mathrm{mL}\right)$. Leukocyte and platelet returned to normal 2 weeks after diagnosis and treatment. However, the patient then experienced another course of anemia with reduction of hemoglobin level to $75 \mathrm{~g} / \mathrm{L}$. This could be due to the reactivation of EBV because plasma EBV-DNA level increased to $2.3 \times 10^{3}$ copies $/ \mathrm{mL}$. PVB19-DNA level did not increase at this time $\left(9.7 \times 10^{2}\right.$ copies $\left./ \mathrm{mL}\right)$. She was re-treated with three cycles of IVIG ( $2.5 \mathrm{~g}$ per day for 7 day).The patient responded well to IVIG with an increase of hemoglobin level to $107 \mathrm{~g} / \mathrm{L}$ on the next month. PVB19-DNA level was remained a low level $\left(3.33 \times 10^{2}\right.$ copies $\left./ \mathrm{mL}\right)$ for 16 months before clearance. However, the patient's condition was stable and did not have anemia during this period of time.

\section{Discussion}


105

106

107

PVB19 is a small, non-enveloped virus that has a diameter of approximately $23-26$ $\mathrm{nm}$ and contains a linear single-stranded DNA genome of $5.6 \mathrm{~kb}$, flanked by two identical terminal hairpin structures. PVB19 infection causes a wide range of pathological conditions: fifth disease in children, persistent anemia in immunocompromised patients, transient aplastic crises, hydrops fetalis in pregnant women, cardiomyopathy and arthropathy[8-11]. PVB19V infection is more susceptible in the immunocompromised hosts including recipients of HSCT. To understand the etiology and pathogenesis of PVB19V infection and the latest recommendations on the treatment of PVB19V-related diseases in HSCT recipients, we searched for articles written in English that were published between 1990 and December 2019 using "PVB19V infection", and/or "bone marrow transplantation", and/or stem cell transplantation, and /or haematopoietic stem cell transplantation on PUBMED. A total of 31 cases from 15 article were found. A summary of these cases and the current case is shown in Table 1.

The time of the onset of PVB19 disease range from 0.03 to 96 months after HSCT.

Rash and cytopenia are the main manifestations of PVB19 infection (26/32 cases)[12-16], followed by other symptoms including arthralgia, malaise, headache, myalgia, and pruritus[17-24]. Four of the 32 patients developed organ failure involving the heart, the lungs, or the kidneys[21, 24],among which three patients also had cytopenia. In addition, cytopenia is more likely to be observed in HSCT recipients 3 months after transplant. In the current case, the key presenting abnormalities of the patient were the anemia and fatigue, and no other obvious 
positive signs.Generally, the diagnosis of PVB19 based on clinical symptoms and laboratory examinations. Bone marrow examination is required for diagnosis of PVB19 infection. Patients with erythroid hypoplasia and lack of maturation of proerythroblasts should be considered for further analysis to confirm or exclude PVB19 infection.Serological examinations of PVB19 IgG and IgM, and PCR-based testing of PVB19-DNA are commonly used in the diagnosis of PVB19 infection. Unlike serological examination, PCR-based analysis can be applied to samples collected from almost all sites of infection other than the peripheral blood. However, the sensitivity of either method was not high. Of all of the reported cases, only half of the patients were tested positive by serological examination. Moreover, the use of serological examination may be hampered in HSCT recipients because of the impaired humoral response due to the use of immunosuppressant. PCR-based examination is the method recommended for HSCT recipients, however, may have an even lesser sensitivity. In a cohort of 53 pediatric (of 195) patients HSCT recipients, only $30 \%$ of patients were tested positive for PVB19-DNA by qPCR, pre-HSCT (9/53), and at 1 (6/53), 2 (4/53) and 3 months (1/25) post HSCT, respectively[25].

The advancement of Metagenomic Next-Generation Sequencing (mNGS) can detect PVB19-DNA from various types of specimens with high sensitivity and specificity. However, it is recommended to test samples that are collected from the sites of suspected PVB19 infection. PCR can involve numerous individual tests for specifically targeted organisms but may still miss a rare pathogen or use primers containing mismatches to the microbial strain involved, which decreases the 
sensitivity of detection[26]. However, conventional testing methods is the limitation in the breadth of pathogens detected, and clinicians are often left with negative results. A chief advantage of mNGS is unbiased sampling, which enables broad identification of known as well as unexpected pathogens or even the discovery of new organisms[27]. Another advantage of mNGS is that it can provide the auxiliary genomic information necessary for evolutionary tracing[28], strain identification [29, 30], and prediction of drug resistance[31]. NGS can provide quantitative or semiquantitative data regarding the concentration of organisms in the sample via the counting of sequenced reads, which is useful for polymicrobial samples or in cases in which more than one pathogen has been implicated in the disease process[32, 33].

Thus, early application of NGS in patients with suspected PVB19 infection can provide timely and adequate guidance for the diagnosis of PVB19 infection. There is no specific antiviral treatment against PVB19. IVIG remains the recommended treatment for patients with PVB19 infection. It is also recommended to reduce the use of immunosuppressive reagents in HSCT recipients with consideration of the presence of other transplant-related complications such as graft versus host diseases. However, the efficacy of IVIG varies between patients and the mechanism behind this is still unclear. In the summary, we observed that 14 out of 25 patients achieved good response to IVIG, with remission of cytopenia and resolution of PVB19 infection related symptoms. Moreover, patients with high levels of viremia tend to have poorer response to IVIG and repeated use of IVIG may be considered for patients that have persistent PVB19 infection and those that are not responded well for the initial 
171 treatment. However, these are based on small number of case reports hence require

172 larger cohort studies for confirmation.

173 An early study showed that antisera resulting from immunization with

174 baculovirusderived B19V VP1-containing VLP capsids neutralized B19V infection of

175 human erythroid progenitor cells, highlighting that VP1-containing VLPs are

176 applicable as a human vaccine for preventing B19V infection[34, 35]. In recent years,

177 in addition to immunoglobulins, some compounds have been shown to possess

178 inhibitory activity against PVB19. Hydroxyurea is an antiproliferative drug used in

179 the treatment of sickle-cell disease that also possesses inhibitory activity against B19V.

180 The nucleotide analogues Cidofovir and its lipid conjugate Brincidofovir are

181 broad-range antivirals mostly active against dsDNA viruses, which showed an

182 antiviral activity also against B19V. Newly synthesized coumarin derivatives offer

183 possibilities for the development of molecules with antiviral activity[36].

\section{Conclusion}

185 In conclusion, PVB19 infection is rare but can cause life-threatening complications in 186 patients that received HSCT. Post-transplant patients presented with anemia should be 187 carefully evaluated to exclude the PVB19 infection. Multiple approaches including 188 the use of NGS should be considered to enhance the accuracy of detection of PVB19. 189 Timely and adequately treatment of IVIG may prevent severe complications.

\section{Abbreviations}

192 ATG: rabbit anti-human thymocyte immunoglobulin; Bu: busulfan; 
193

194

195

Cy: cyclophosphamide; EBV: Epstein-Barr virus; EPO: erythropoietin;

Flu: fludarabine; FK506: tacrolimus; GVHD: graft versus host diseases; HSCT: hematopoietic stem cell transplantation; IVIG: intravenous immunoglobulin; MMF: mycophenolate mofetil; MTX: methotrexate; mNGS: Metagenomic Next-Generation Sequencing; PVB19: parvovirus B19; PTCY: post-transplant cyclophosphamide; PRCA: Pure red cell aplasia; Q-PCR: Quantitative polymerase chain reaction; TT: thiotepa

\section{Ethical approval and consent to participate}

Ethical approval is not required for this Case report. Written informed consent was obtained from the patient's parent.

\section{Consent for publication}

Written informed consent was obtained from the patient's parent for publication of this paper and any accompanying images.

\section{Availability of data and materials}

Not applicable.

\section{Competing interests}

The authors have no competing interests to declare.

\section{Funding}

Sanming Project of Medicine in Shenzhen (SZSM201512033), Shenzhen Fund for Guangdong Provincial High-level Clinical Key Specialties (SZGSP012), Shenzhen Key Medical Discipline Construction Fund (SZXK034) and Shenzhen Healthcare 
Research Project (SZLY2018015) supported the genetic assessment and data analysis for this paper.

\section{Authors' contributions}

Both Xiaohui Zhou and Uet Yu drafted this manuscript. Xiaodong Wang provided the concept for this paper. Chunjing Wang Chunlan Yang, Mingjing Luo, Yue Li, Qian Zhang, Xiaoling Zhang, Yu Zhang, Zhenhu Lin and Xianping Jiang contributed to the laboratory examination and data analysis for this paper. Sixi Liu gave critical review to the manuscript.

\section{Acknowledgements}

We thank Prof Kuang-Yueh Chiang from the Hospital for Sick Children in Toronto, Canada for the long-time support to help us to provide better care for our pediatric transplant patients.

\section{References:}

1. Bittencourt H, Rocha V, Filion A, Ionescu I, Herr AL, Garnier F, Ades L, Esperou H, Devergie A, Ribaud P et al: Granulocyte colony-stimulating factor for poor graft function after allogeneic stem cell transplantation: 3 days of G-CSF identifies long-term responders. Bone Marrow Transplant 2005, 36(5):431-435.

2. Bruno B, Gooley T, Sullivan KM, Davis C, Bensinger WI, Storb R, Nash RA: Secondary failure of platelet recovery after hematopoietic stem cell transplantation. Biol Blood Marrow Transplant 2001, 7(3):154-162.

3. Peralvo J, Bacigalupo A, Pittaluga PA, Occhini D, Van Lint MT, Frassoni F, Nardelli E, Transino A, Pantarotto M, Marmout AM: Poor graft function associated 
with graft-versus-host disease after allogeneic marrow transplantation. Bone Marrow Transplant 1987, 2(3):279-285.

4. Salzberger B, Bowden RA, Hackman RC, Davis C, Boeckh M: Neutropenia in allogeneic marrow transplant recipients receiving ganciclovir for prevention of cytomegalovirus disease: risk factors and outcome. BLOOD 1997, 90(6):2502-2508.

5. Torok-Storb

B, Boeckh M, Hoy

C, Leisenring W, Myerson

D, Gooley T: Association of specific cytomegalovirus genotypes with death from myelosuppression after marrow transplantation. BLOOD 1997, 90(5):2097-2102.

6. Karrasch M, Schmidt V, Hammer A, Hochhaus A, Rosee P, Petersen I, Sauerbrei A, Baier M, Sayer HG, Hermann B: Chronic persistent parvovirus B19 bone marrow infection resulting in transfusion-dependent pure red cell aplasia in multiple myeloma after allogeneic haematopoietic stem cell transplantation and severe graft versus host disease. HEMATOLOGY 2017, 22(2):93-98.

7. Wang X, Zhang X, Yu U, Wang C, Yang C, Li Y, Li C, Wen F, Li C, Liu S: Co-Transplantation of Haploidentical Stem Cells and a Dose of Unrelated Cord Blood in Pediatric Patients with Thalassemia Major. CELL TRANSPLANT 2021, $30: 2139987512$.

8. Cossart YE, Field AM, Cant B, Widdows D: Parvovirus-like particles in human sera. LANCET 1975, 1(7898):72-73.

9. Cotmore SF, Agbandje-McKenna M, Chiorini JA, Mukha DV, Pintel DJ, Qiu J, Soderlund-Venermo M, Tattersall P, Tijssen P, Gatherer D et al: The family Parvoviridae. ARCH VIROL 2014, 159(5):1239-1247. 

MICROBIOL REV 2017, 30(1):43-113.

11. Simpson KE, Storch GA, Lee CK, Ward KE, Danon S, Simon CM, Delaney JW, Tong A, Canter CE: High Frequency of Detection by PCR of Viral Nucleic Acid in The Blood of Infants Presenting with Clinical Myocarditis. PEDIATR CARDIOL 2016, 37(2):399-404.

12. Katoh D, Ochi Y, Hiramoto N, Morita M, Yabushita T, Shimomura Y, Yamashita

D, Ono Y, Yoshioka S, Yonetani N et al: Parvovirus B19 infection in adult patients after allogeneic stem cell transplantation: our experience of five cases and literature review. Bone Marrow Transplant 2020, 55(3):653-656.

13. Muetherig A, Christopeit M, Muller LP, Grothe W, Weber T, Theurich S, Behre

G: Human parvovirus B19 infection with GvHD-like erythema in two allogeneic stem cell transplant recipients. Bone Marrow Transplant 2007, 39(5):315-316. viraemia associated with pure red cell aplasia after allogeneic bone marrow transplantation. J CLIN VIROL 2004, 31(1):16-19. 15. Schleuning M, Jager G, Holler E, Hill W, Thomssen C, Denzlinger C, Lorenz T, Ledderose G, Wilmanns W, Kolb HJ: Human parvovirus B19-associated disease in 278 bone marrow transplantation. INFECTION 1999, 27(2):114-117. 16. Tsirigotis P, Girkas K, Economopoulou C, Bouchla A, Papanicolaou N, 
Rep Transplant 2011, 2011:251930.

17. Cohen BJ, Beard S, Knowles WA, Ellis JS, Joske D, Goldman JM, Hewitt P, Ward KN: Chronic anemia due to parvovirus B19 infection in a bone marrow transplant patient after platelet transfusion. TRANSFUSION 1997, 37(9):947-952.

18. Hayes-Lattin B, Seipel TJ, Gatter K, Heinrich MC, Maziarz RT: Pure red cell aplasia associated with parvovirus B19 infection occurring late after allogeneic bone marrow transplantation. AM J HEMATOL 2004, 75(3):142-145.

19. Hsu JW, Czander M, Anders V, Vogelsang G, Brodsky RA: Parvovirus b19-associated pure red cell aplasia in chronic graft-versus-host disease. $\mathrm{Br} \mathrm{J}$ Haematol 2002, 119(1):280-281.

20. Karrasch M, Schmidt V, Hammer A, Hochhaus A, Rosee P, Petersen I, Sauerbrei A, Baier M, Sayer HG, Hermann B: Chronic persistent parvovirus B19 bone marrow infection resulting in transfusion-dependent pure red cell aplasia in multiple myeloma after allogeneic haematopoietic stem cell transplantation and severe graft versus host disease. HEMATOLOGY 2017, 22(2):93-98.

21. Klumpen HJ, Petersen EJ, Verdonck LF: Severe multiorgan failure after parvovirus B19 infection in an allogeneic stem cell transplant recipient. Bone Marrow Transplant 2004, 34(5):469-470.

22. Soderlund M, Ruutu P, Ruutu T, Asikainen K, Franssila R, Hedman K: Primary and secondary infections by human parvovirus B19 following bone marrow transplantation: characterization by PCR and B-cell molecular immunology. Scand J Infect Dis 1997, 29(2):129-135. 
23. Wasak-Szulkowska E, Grabarczyk P, Rzepecki P: Pure red cell aplasia due to parvovirus B19 infection transmitted probably through hematopoietic stem cell transplantation. TRANSPL INFECT DIS 2008, 10(3):201-205.

24. Weiland HT, Salimans MM, Fibbe WE, Kluin PM, Cohen BJ: Prolonged parvovirus B19 infection with severe anaemia in a bone marrow transplant patient. $\mathrm{Br}$ J Haematol 1989, 71(2):300.

25. Rahiala J, Koskenvuo M, Norja P, Meriluoto M, Toppinen M, Lahtinen A, Vaisanen E, Waris M, Vuorinen T, Saarinen-Pihkala U et al: Human parvoviruses B19, PARV4 and bocavirus in pediatric patients with allogeneic hematopoietic SCT. Bone Marrow Transplant 2013, 48(10):1308-1312.

26. Wilson MR, Naccache SN, Samayoa E, Biagtan M, Bashir H, Yu G, Salamat SM, Somasekar S, Federman S, Miller S et al: Actionable diagnosis of neuroleptospirosis by next-generation sequencing. N Engl J Med 2014, 370(25):2408-2417.

27. Chiu CY: Viral pathogen discovery. CURR OPIN MICROBIOL 2013, 16(4):468-478.

28. Gire SK, Goba A, Andersen KG, Sealfon RS, Park DJ, Kanneh L, Jalloh S, Momoh M, Fullah M, Dudas G et al: Genomic surveillance elucidates Ebola virus origin and transmission during the 2014 outbreak. SCIENCE 2014, 345(6202):1369-1372.

29. Deurenberg RH, Bathoorn E, Chlebowicz MA, Couto N, Ferdous M, Garcia-Cobos S, Kooistra-Smid AM, Raangs EC, Rosema S, Veloo AC et al: Application of next generation sequencing in clinical microbiology and infection 
prevention. J BIOTECHNOL 2017, 243:16-24.

30. Salipante SJ, SenGupta DJ, Cummings LA, Land TA, Hoogestraat DR, Cookson BT: Application of whole-genome sequencing for bacterial strain typing in molecular epidemiology. J CLIN MICROBIOL 2015, 53(4):1072-1079.

31. Sahoo MK, Lefterova MI, Yamamoto F, Waggoner JJ, Chou S, Holmes SP, Anderson MW, Pinsky BA: Detection of cytomegalovirus drug resistance mutations by next-generation sequencing. J CLIN MICROBIOL 2013, 51(11):3700-3710.

32. Salipante SJ, Hoogestraat DR, Abbott AN, SenGupta DJ, Cummings LA, Butler-Wu SM, Stephens K, Cookson BT, Hoffman NG: Coinfection of Fusobacterium nucleatum and Actinomyces israelii in mastoiditis diagnosed by next-generation DNA sequencing. J CLIN MICROBIOL 2014, 52(5):1789-1792.

33. Gu W, Miller S, Chiu CY: Clinical Metagenomic Next-Generation Sequencing for Pathogen Detection. Annu Rev Pathol 2019, 14:319-338.

34. Bansal GP, Hatfield JA, Dunn FE, Kramer AA, Brady F, Riggin CH, Collett MS, Yoshimoto K, Kajigaya S, Young NS: Candidate recombinant vaccine for human B19 parvovirus. J INFECT DIS 1993, 167(5):1034-1044.

35. Kajigaya S, Fujii H, Field A, Anderson S, Rosenfeld S, Anderson LJ, Shimada T, Young NS: Self-assembled B19 parvovirus capsids, produced in a baculovirus system, are antigenically and immunogenically similar to native virions. Proc Natl Acad Sci U S A 1991, 88(11):4646-4650.

36. Manaresi E, Gallinella G: Advances in the Development of Antiviral Strategies against Parvovirus B19. Viruses 2019, 11(7). 

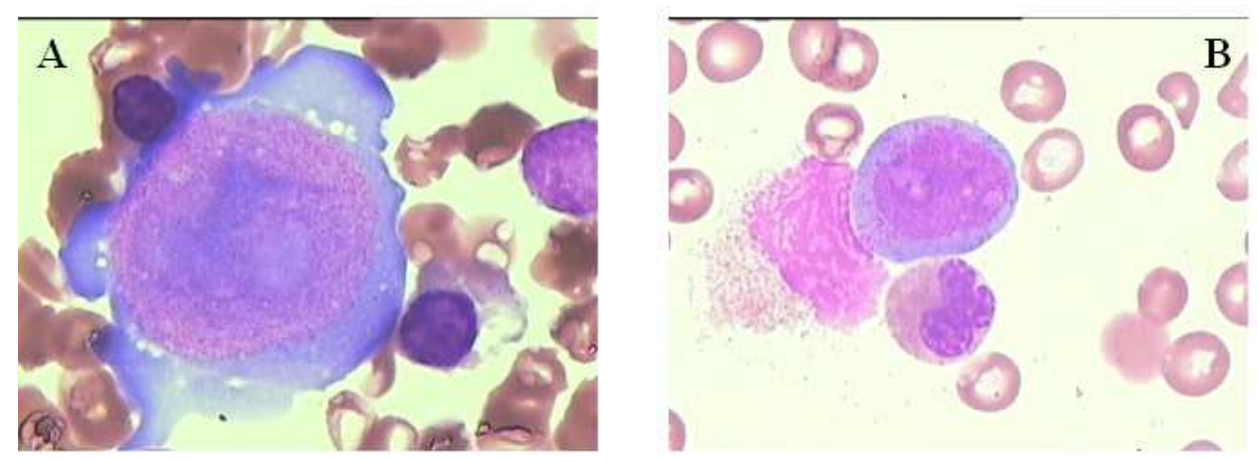

349

350

351

352

353

354

\section{Figure 1}

Morphological examination of the bone marrow aspiration showed (Wright-Giemsa stain,x1000) normal granulopoiesis and megakaryopoiesis(A), but reduced erythropoiesis Grant proerythroblasts with basophilic cytoplasm(B).
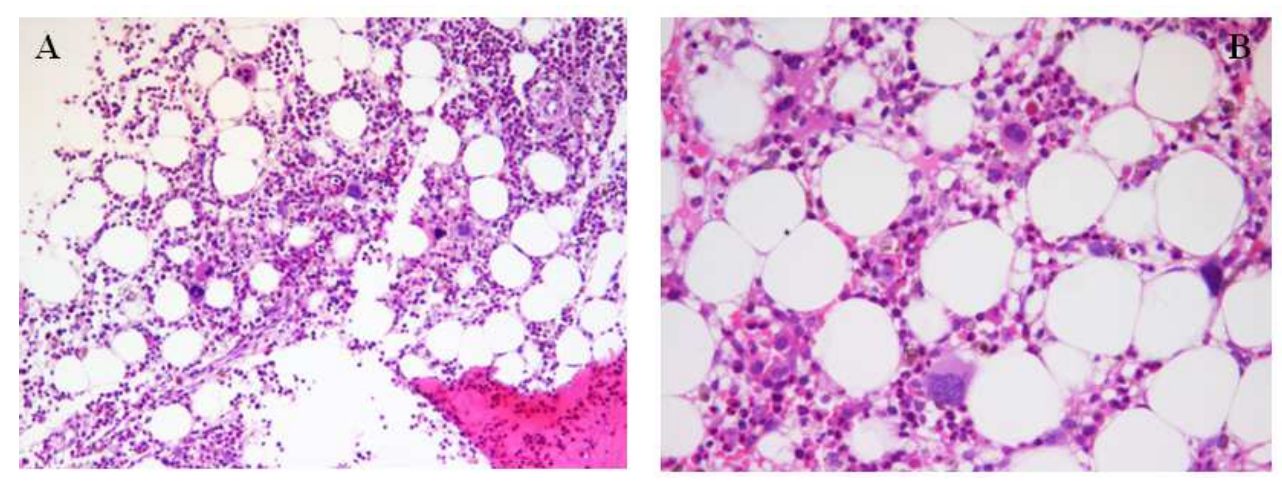

\section{Figure 2}

Bone marrow biopsy showing mild hypoplasia of hematopoietic tissue by hematoxylin $\operatorname{eosin}(\mathrm{HE})$ staining(A,x5 and $\mathrm{B}, \mathrm{x} 10)$. 


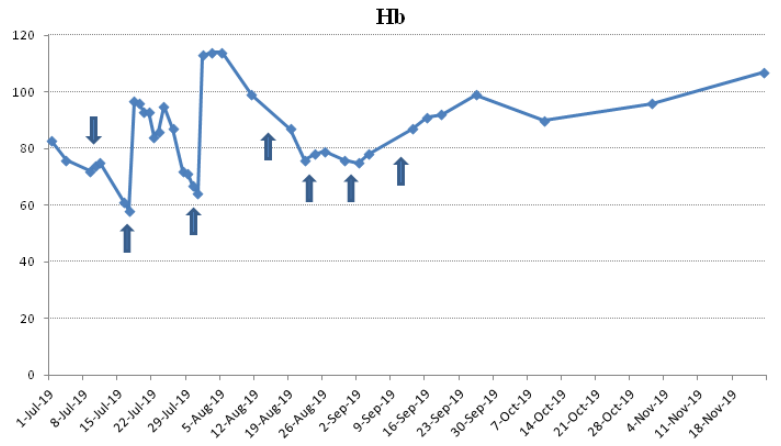

PLT
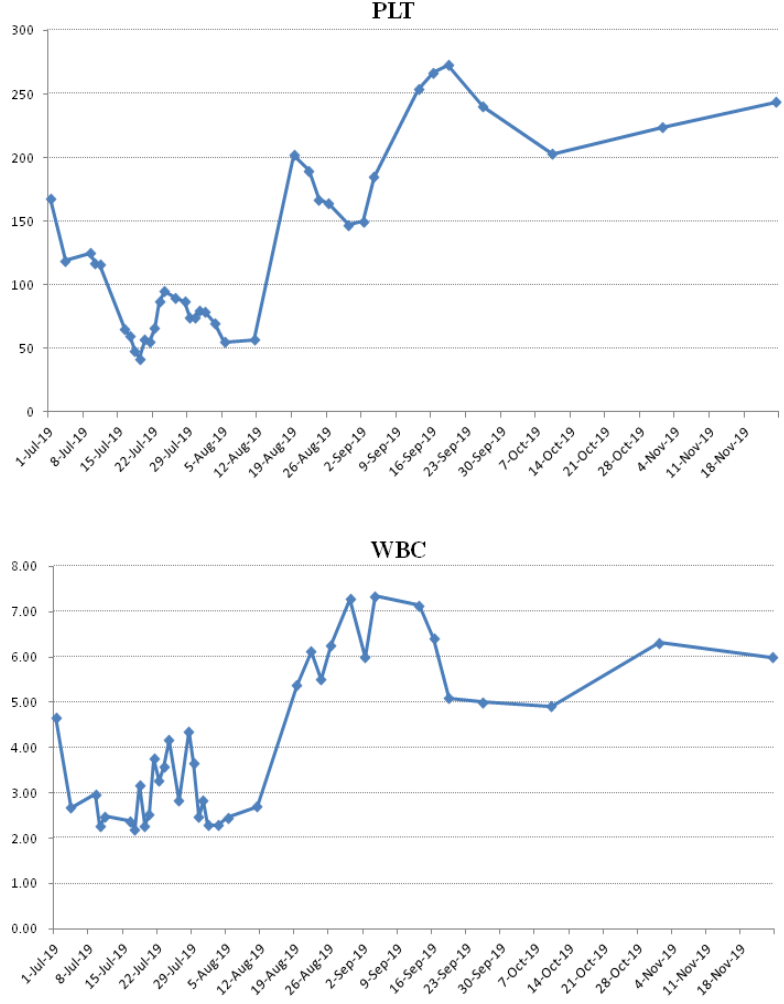

Figure 3

Correlation of laboratory values (white blood cell, hemoglobin and platelet) and IVIG

369 treatment during diagnosis.

370 WBC: white blood cell; Hb: hemoglobin; PLT: platelet;

371 『:intravenous immunoglobulin 
Number of patients

\section{Patients}

Age (y), median (range)

38(4-59)

Sex, (male/female)

$18: 12$ a

\section{Donor}

Allo-SCT

Auto-SCT

2

\section{Hematological disease}

CML

AML

ALL

6

Lymphoma 3

thalassemia major

1

Others

6

Onset (months) after HSCT,median (range)

4 months, $\left(0.03^{\mathrm{b}}-96 \mathrm{~ms}\right)$

0-3 months after HSCT

$>3$ months after HSCT

18

Dection of PVB19 IgG at onset of disease

Positive/negative

Dection of PVB19 IgM at onset of disease

Positive/negative

Positive PVB19 PCR result at onset of disease

Positive/negative

\section{Symptom}

Rash

Cytopenia

Organ failure

\section{Sample}

Blood 
Skin

Other specimens

\section{Organ}

Lung 2

Heart and lung $\quad 1$

Lung and kindey 1

Treatment

No treatment

$\begin{array}{ll}\text { IVIG } & 18\end{array}$

$\begin{array}{ll}\text { IVIG and IS reduction } & 7\end{array}$

Recurrence fo PVB19 infection

$\begin{array}{ll}\text { IVIG } & 22\end{array}$

\section{Outcome}

$\begin{array}{ll}\text { Alive } & 24\end{array}$

$\begin{array}{ll}\text { Dead } & 7\end{array}$

Table 1

377 Clinical characteristics of 31 patients with parvovirus B19 disease after allogeneic

378 hematopoietic stem cell transplantation

$379 \quad \mathrm{ALL}=$ acute lymphoblastic leukemia

$380 \quad \mathrm{AML}=$ acute myeloid leukemia

381 Allo-SCT=allogeneic stem cell transplantation

382 Auto-SCT $=$ autologous stem cell transplantation

$383 \mathrm{CML}=$ chronic myeloid leukemia

384 HSCT=hematopoietic stem-cell transplantation

$385 \quad \mathrm{IVIG}=$ intravenous immunoglobulin

386 IS=immunosuppressant

387 MPAL=mixed-phenotype acute leukemia; $\mathrm{Hgb}=$ hemoglobin

$388 \quad \mathrm{~PB}=$ peripheral blood

389 PVB19=parvovirus B19 
390 a: one case was gender unknown.

391 b: before stem cell transplantation

392 c: one patient was weak positive, seventeen patients PVB19 IgG was not mentioned;

393 one patient was not test

394 d:one patient was weak positive, sixteen patients PVB19 IgG was not mentioned; one 395 patient was not test; one patient was equivocal

396 e: one patient PCR was not mentioned; one patient was not test

397 f: One patient did not mention whether to treat 


\section{Figures}
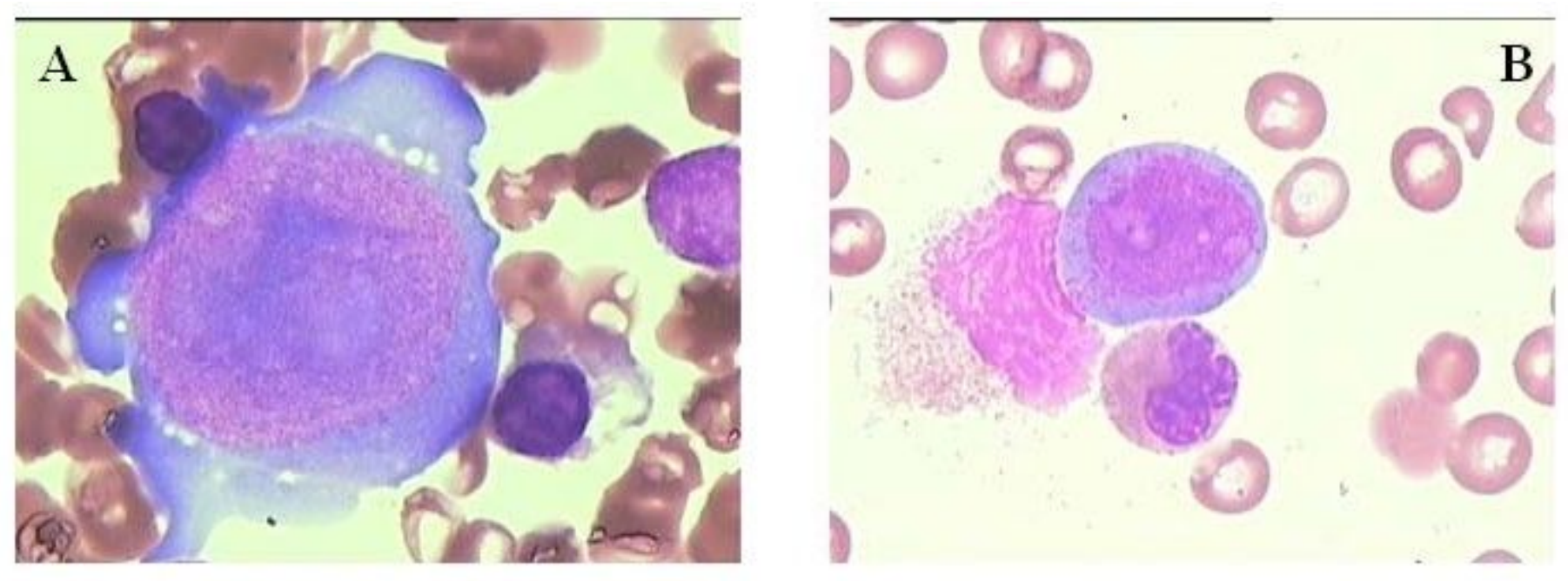

Figure 1

Morphological examination of the bone marrow aspiration showed (Wright-Giemsa stain, x1000) normal granulopoiesis and megakaryopoiesis(A), but reduced erythropoiesis Grant proerythroblasts with basophilic cytoplasm(B).
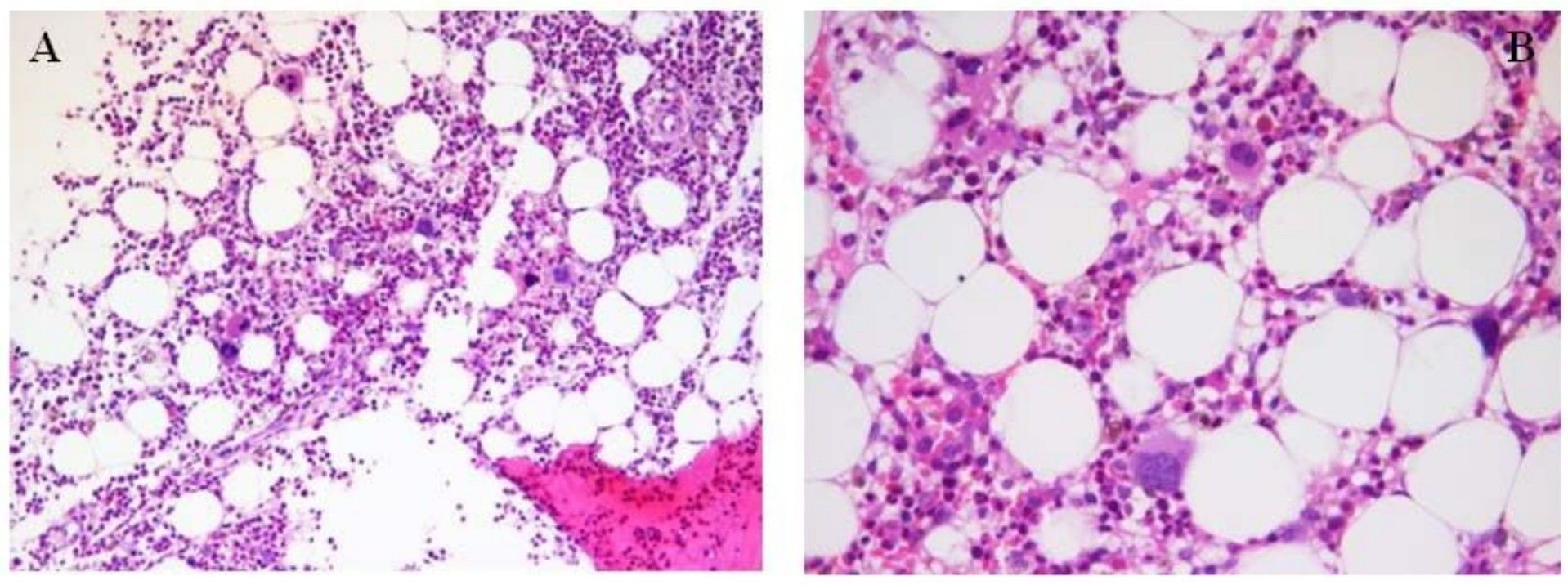

Figure 2

Bone marrow biopsy showing mild hypoplasia of hematopoietic tissue by hematoxylin eosin(HE) staining $(A, x 5$ and $B, x 10)$. 

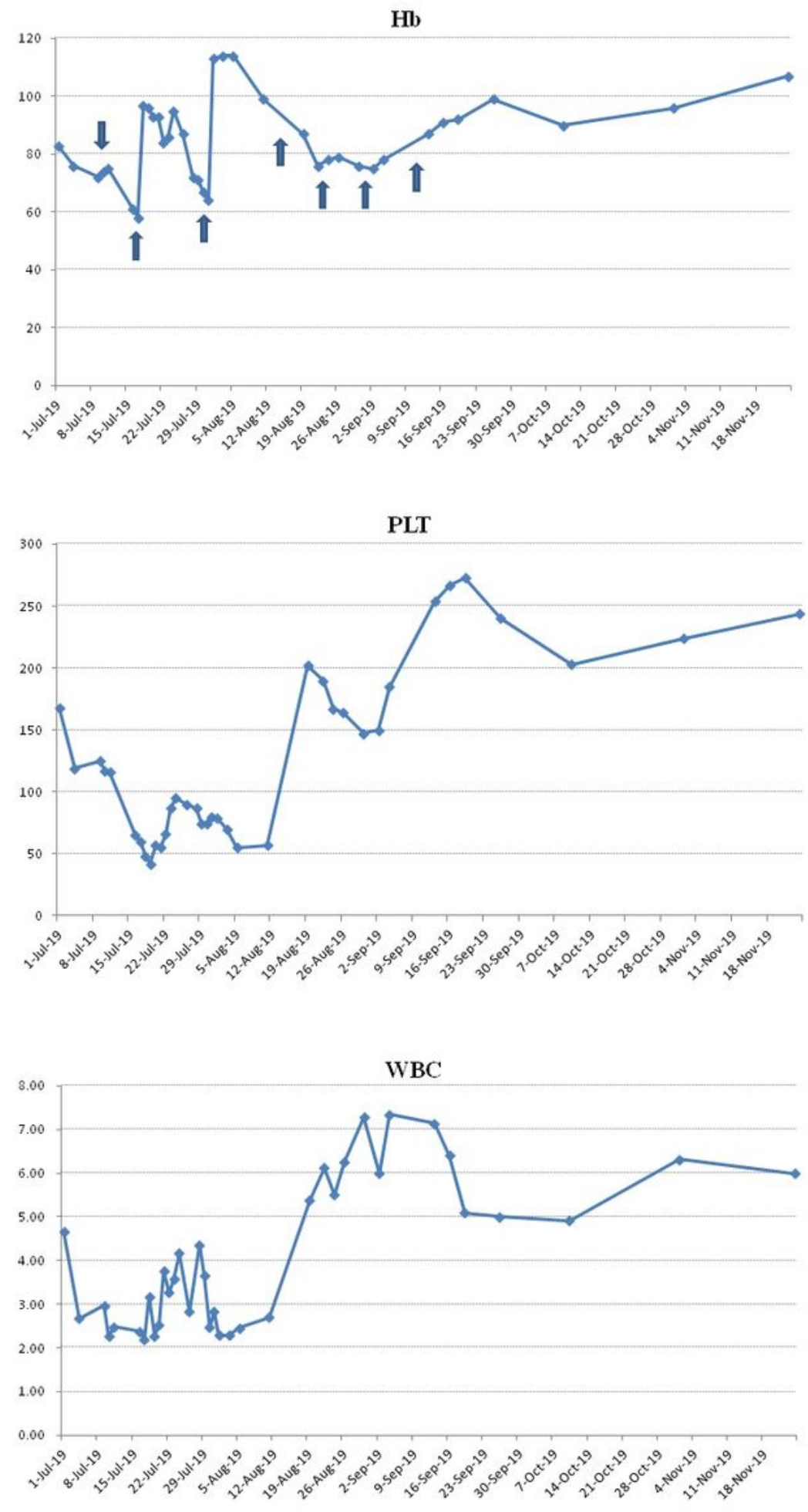

\section{Figure 3}

Correlation of laboratory values (white blood cell, hemoglobin and platelet) and IVIG treatment during

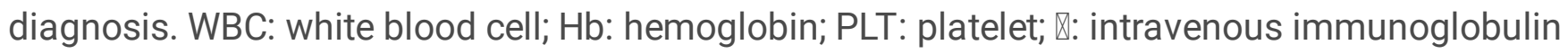

\section{Supplementary Files}


This is a list of supplementary files associated with this preprint. Click to download.

- CAREchecklistEnglish2013.pdf 